\title{
The Impact of Different Genres of Music on Teenagers
}

\author{
Junle Richard Chen ${ }^{1}$ \\ ${ }^{1}$ The Hun School of Princeton, New Jersey, United States \\ Correspondence: Junle Richard Chen, The Hun School of Princeton, 176 Edgerstoune Rd, Princeton, NJ \\ 08540, United States. E-mail: junlechen@hunschool.org
}

Received: October 15, 2018

Accepted: November 5, 2018

Online Published: November 7, 2018

doi:10.5539/ijps.v10n4p42

URL: https://doi.org/10.5539/ijps.v10n4p42

\begin{abstract}
The purpose of this study was to determine the impact of different genres of music (Jazz, Hip-hop, Pop, Classical) on the cognitive abilities, calmness, stress, mood, and energy of adolescents. Utilizing Muse Headband, an EEG Monitoring app, and Sennheiser headphone, volunteers completed a designed experimental protocol and were tested on the aforementioned variables. The study found that all music indicated a trend of improved energy, stress, mood, and calmness. Although some of the results were insignificant, the consistency of the results suggests correlations between (a) calmness and cognitive abilities, (b) stress and calmness, (c) mood and energy level, and (d) calmness and energy level.
\end{abstract}

Keywords: music, calmness, cognitive ability, stress, teenager, energy, mood

\section{Introduction}

Music, as a form of art, is created when different sounds are combined to create a new sound that is euphonic. Every piece of music has six essential elements: rhythm, dynamics, melody, harmony, texture, and form. Each distinct genre of music combines these elements differently. Genres of music include Classical, Jazz, Hip-hop, Pop, and many other categories. Classical music, compared to other genres of music, has a larger dynamic range, longer duration, and greater notational precision. Hip-hop has a stronger beat than other genres of music. Jazz music has frequently-changing melodies and improvisations. Pop music, although it varies across different eras, usually lasts for about two to five minutes and often has more memorable melodies than other music.

As music has become more accessible, it is increasingly common to see people listening to music in public, whether in the airport or on the street. At the same time, people have displayed increasing interest in the benefits of listening to music. The widespread interest in the benefits that music listening can bring started after the publication of an article that stated that people who listen to Mozart have a better spatial ability (Jenkins, 2001). Although this so-called "Mozart Effect" does demonstrate immediate benefits after listening to music, this only lasts for about 10 to 15 minutes. In the following years, other researchers studied the links between music and other benefits from listening to music, including improved work performance, creativity, and mood. Creativity — defined as the ability to turn inventive and imaginative ideas into reality - is negatively impacted by stress and negative mood (Ciotti, 2015). As people listen to music, however, their stress levels decrease and their mood improves, which can in turn increase their creativity (Lesiuk, 2005). Researches also indicates that music can significantly increase work quality and how listening to music can "lead to short-term and long-term cognitive benefits" such as memorization (Schellenberg, 2004).

However, different genres of music likely have different impacts on people. Teenagers studying for the SAT or other standardized tests might listen to music that boosts concentration. Athletes who are playing games or practicing might listen to music that can help them become more excited. The purpose of this research is to determine the impacts of different genres of music on cognitive abilities, stress, mood, and energy in adolescents. We utilized Muse - a headband that helps users become calmer by providing feedback from EEG data it collects - as well as other equipment, such as headphone and EEG monitor, to expose students to different genres of music in an experimental protocol and to collect data. Data were collected in a soundproof room in a school library with students during a summer school program. Data of energy level, stress level, mood, EEG, and calmness were analyzed, which provide evidence for different impacts of different genres of music on teenagers. 


\section{Prior Work}

Electroencephalogram (EEG) is a test that is used to monitor electrical activity in the brain. Electrodes are attached to the scalp to analyze and record brain waves. Considerable research shows that EEG can effectively record different emotional states and stress levels. Specifically, this research study uses the Muse headset and Muse Monitor app for recording and analyzing EEG. Muse is a brain-sensing headband that helps users have better meditation experiences by giving them real-time EEG feedback and meditation advice. It has four EEG sensors: three Reference Sensors, two Forehead Sensors, and two SmartSense Conductive Rubber Ear Sensors. Evidence demonstrates that Muse can provide accurate and high-quality EEG data (Krigolson, 2017). Since other research provides a strong validation of the reliability of both EEG and Muse, it is legitimate to use Muse for collecting EEG data and analyzing EEG to identify changes in participants' levels of emotion and calmness.

From present and past studies, it is known that music can impact individuals' emotion, mood, stress, and cognitive abilities. When listening to music, the listener creates a bond with the composer; the composer embodies his emotion, memory, and imagination while the listeners perceive the emotion in the music, thus resonating with the composer (Bennett, 1942).Music can "evoke the full range of human emotion from sad, nostalgic, and tense, to happy, relaxed, calm, and joyous," which can greatly affect listeners' emotion and mood (Ahtisaari, 2015). The emotions evoked by music can be both positive and negative emotions (Schaeffer, 2017). At the same time, music can subdue the impact of stressors on individuals' stress and anxiety (Knight and Richard, 2001). Studies on the effects of music on stress stated that "music listening impacted the psychobiological stress system" (Thoma, 2013). Several empirical studies, such as Jenkins's research on the Mozart effect and Schellenberg's study on music and IQ, have shown that listening to music can improve individuals' spatial IQ and other cognitive abilities (Jenkins, 2001 \& Schellenberg, 2013). Many researches used EEG to analyze the effect of music on emotion and brain (Ramirez, 2018). In sum, previous research indicates that music can improve stress levels, mood, emotion, and cognitive abilities.

The purpose of this study is to test the impacts of different genres of music on teenagers' cognitive abilities, mood, stress, energy levels. Four distinct music genres were selected for the experiment: Classical, Jazz, Hip-hop, and Pop. According to Shigeki Ogata's paper on EEG and music, EEG varies according to "the combination of music's components, i.e., rhythm, melody, and harmony" (Ogata, 1995). Classical music is usually with clear rhythm, tuneful melodies, and played by piano or classical instruments. Jazz usually has more syncopations, improvisation, and dynamic rhythms. For this research, Swing Jazz, which is defined by "a rhythm section [that] smoothly accentuates each beat in $4 / 4$ or a 'swinging' rhythmic pattern", is chosen for the Jazz genre (Apell, 1955). Hip-hop has a powerful beat, chanted and simple lyrics, and a simple melody (Harvard Dictionary of Music). Pop music, "a musical idiom of recent centuries whose mass disseminated works appeal to a broad public" has a bright melody and rhyme, but different music regression than Jazz or Classical Music (Apell, 1955). These four genres of music have distinct and different rhythms, melodies, and harmonies, making them distinguishable for testing purposes.

This research aims to determine the impacts of different genres of music on cognitive abilities, stress, mood, and energy in adolescents, providing insights into the potential benefits of listening to different genres of music for different occasions.

\section{Methods}

\subsection{Stage One}

\subsubsection{Purpose}

The purpose of Stage One is to determine the impact of different genres of music on stress level, energy level, mood, and calmness of the participants, and to then select two genres of music that have opposite effects on the energy levels of participants. This stage included four independent variables and two dependent variables. The four genres of music (Jazz, Classical, Hip-hop, Pop) are the independent variables. Survey results and EEG data from Muse are the dependent variables.

\subsubsection{Participants}

Stage one had 60 participants in total: 30 men and 30 women. The participants' ages ranged from 14 to 17 years old. All participants were randomly divided into four music genre groups (Jazz, Classical, Hip-hop, Pop) so that each group included 15 participants. In each group, participants listened to a piece of music from the genre of music they were assigned to. Participants in the classical group listened to music that had a more regular and traditional melody, and mostly played by an orchestra. Participants in the Jazz group listened to 
pieces consisting of swing beats, blues elements, and improvisations. Participants in the pop group listened to music that had a memorable melody with strong beats and rhythms. Participants in the Hip-hop group listened to music that consisted of chanted lyrics, strong beats, and repeating background music.

\subsubsection{Materials}

The musical app NetEase Music did the randomization of the songs; different pieces were put into the four different playlists according to their genres. All the participants in Stage One were tested in the same location (a soundproof room) and during the same time of the day (1:00 p.m. to 3:00 p.m.) throughout two consecutive days. Sennheiser headphones connected to an iPad provided all Sound stimuli.

\subsubsection{Procedure}

The experiment was performed as follows. Participants were given a short and basic survey with three short questions. The survey asked about the energy level, stress level, and mood of the participants on a scale of one to five. For energy level, "one" represented very tired or exhausted, and "five" represented very energetic or excited. For stress level, "one" represented least stressed or depressed, and "five" represented most stressed or depressed. For mood, "one" represented very sad or unhappy, and "five" represented very happy or satisfied. All the numbers between "one" and "five" represent participants' energy level, stress level, and mood between the two extremes. After taking the survey, participants were instructed to put on the Muse headset. After the Muse headset successfully calibrated with participants, the participants put on headphones and listened to a piece of music from the genre they were assigned to while meditating. Each meditating session lasted for three minutes, and all the participants lied back into the chair with their eyes closed. Immediately after the three-minute meditation session, participants took the same survey they took at the start of the experiment. EEG data analyzed by the Muse app were recorded with all the survey data.

\subsection{Stage Two}

\subsubsection{Purpose}

The purpose of Stage Two was to determine the impact of two genres of music identified during Stage One as being either calming or energizing on participants' cognitive ability, specifically their memory. For this experiment, card memorization was chosen for a cognitive/memory test.

\subsubsection{Participants}

Stage two had 20 participants in total, consisting of 10 men and 10 women, all between 14 and 17 years old. Participants were randomly divided into two groups (Jazz and Classical) so that each group included 10 volunteers. Each group listened to the same pieces of music from the same composers for that genre of music from Stage One.

\subsubsection{Materials}

Stage Two was conducted in the same location and during the same time period as the previous stage. In addition to previous equipment, this stage also required the use of a deck of poker. The experiment was conducted in one day.

\subsubsection{Procedure}

Experiments were performed as follows. First, participants were given the same survey that was used in Stage One where they were asked about their energy level, stress level, and mood. Then, 30 cards were selected randomly from a deck of 54 cards. Participants were given one minute to remember as many cards out of 30 cards as possible. The participants did not have to remember colors or suits, but they did need to remember the order of the cards. Three or more consecutive cards counted as a sequence, and the participants had to remember sequences in order to have a valid card count. They also did not have to remember these sequences in a specific orientation; it could be from bottom to top of the deck or from top to bottom. After card memorization, the participants immediately recited the order of the cards or the sequences they remembered out of the 30 cards they were given. Then, participants listened to the theme of music they were assigned to while meditating. The duration of the meditation for all participants was three minutes. All participants rested on their chair with their eyes closed. The same survey taken at the beginning of the stage was administered against immediately after meditation. Lastly, participants repeated the same card-memorizing test. Data on card memorization, survey responses, and EEG were collected. 


\section{Results}

In Stage One, the effects of each music genre on energy level, stress level, mood, and calmness were examined. By comparing EEG data collected from participants in different musical groups, it became clear that those in the Classical music group exhibited the most calmness (Figure 1). However, the survey results showed that classical music had a relatively small impact on improving stress levels compared to other genres (Figure 2). Comparing the average EEG data of all participants on calmness, it was discovered that participants who listened to Hip-hop were least calm. However, comparing the energy change of participants showed that participants who listened to Hip-hop had the highest score in the change of energy, meaning it was best able to excite listeners (Figure 3). Pop music had a minor effect on stress, mood, and energy of the participants compared to other music genres. Lastly, Jazz was able to substantially improve participants' calmness compared to other genres of music (Figure 1). The survey results also showed that Jazz was relatively better at improving stress and mood of the participants than other genres of music. While Classical and Jazz music had a slightly larger impact on calmness, Pop and Hip-hop have slightly greater impacts on increasing energy level (Figures 1 through 4).

The purpose of Stage Two was to build on the findings of Stage One by limiting the four themes of music to the two genres that showed biggest changes in calmness and energy: Jazz and Hip-hop, respectively. A significant finding in Stage Two was the impact of Jazz and Hip-hop on cognitive skills. Participants who listened to Jazz, on average, remembered approximately three cards more than participants who listened to Hip-hop in the second card test. The mean score of participants in the Jazz group was 13.5, while the mean score of participants who listened to Hip-hop was 10.8 (Figure 5). Five out of ten participants who listened to Hip-hop became worse at remembering cards than they were before listening to the music. In comparison, nine out of ten participants who listened to Jazz remembered the same or more cards after listening to music than before. For the change of cards - i.e., the difference between the number of cards remembered by participants in the first card test and second card test - participants in the Jazz group, on average, remembered 1.4 additional cards, while the Hip-hop participants averaged 0.6 fewer (Figure 6). In short, this means that, in the cognitive test, participants who listened to Jazz improved about two cards more than those who listened to Hip-hop.

While Stage Two reinforced some findings of Stage One, the results also show some discrepancies. In Stage Two, the EEG data of participants who listened to Jazz showed a higher calmness level than participants in Hip-hop group (Figure 7). Comparing the survey results on energy, stress, and mood across the genres, participants who listened to Hip-hop scored slightly higher on energy and mood, and participants who listened to Jazz scored better at stress (Figure 8). The average score of participants in the Jazz group demonstrated a more significant improvement in stress levels than participants in the Hip-hop group. All of these results reinforced the findings in Stage One, except for mood improvement. In Stage One, according to the survey results, Jazz has a significantly larger impact on mood improvement than Hip-hop. In Stage Two, on the other hand, Hip-hop showed a slightly larger impact on improving mood than Jazz. This might be caused by the imprecision of the survey or different psychological or physical conditions of participants. The largest possible improvement for stress level on a scale of five is four, and Jazz was only able to improve stress level more than Hip-hop by 0.2 on participants. Hip-hop also only scored 0.2 better score than Jazz on the change of energy level and 0.15 better than Jazz on change of mood (Figure 8).

However, the t-test results all showed insignificant results for independent variables in Stage Two except the score of energy for Hip-hop. Although the results are shown as insignificant, the results for Stage Two are consistent for both genres of music, which suggests that significant results could be found with a larger sample. 


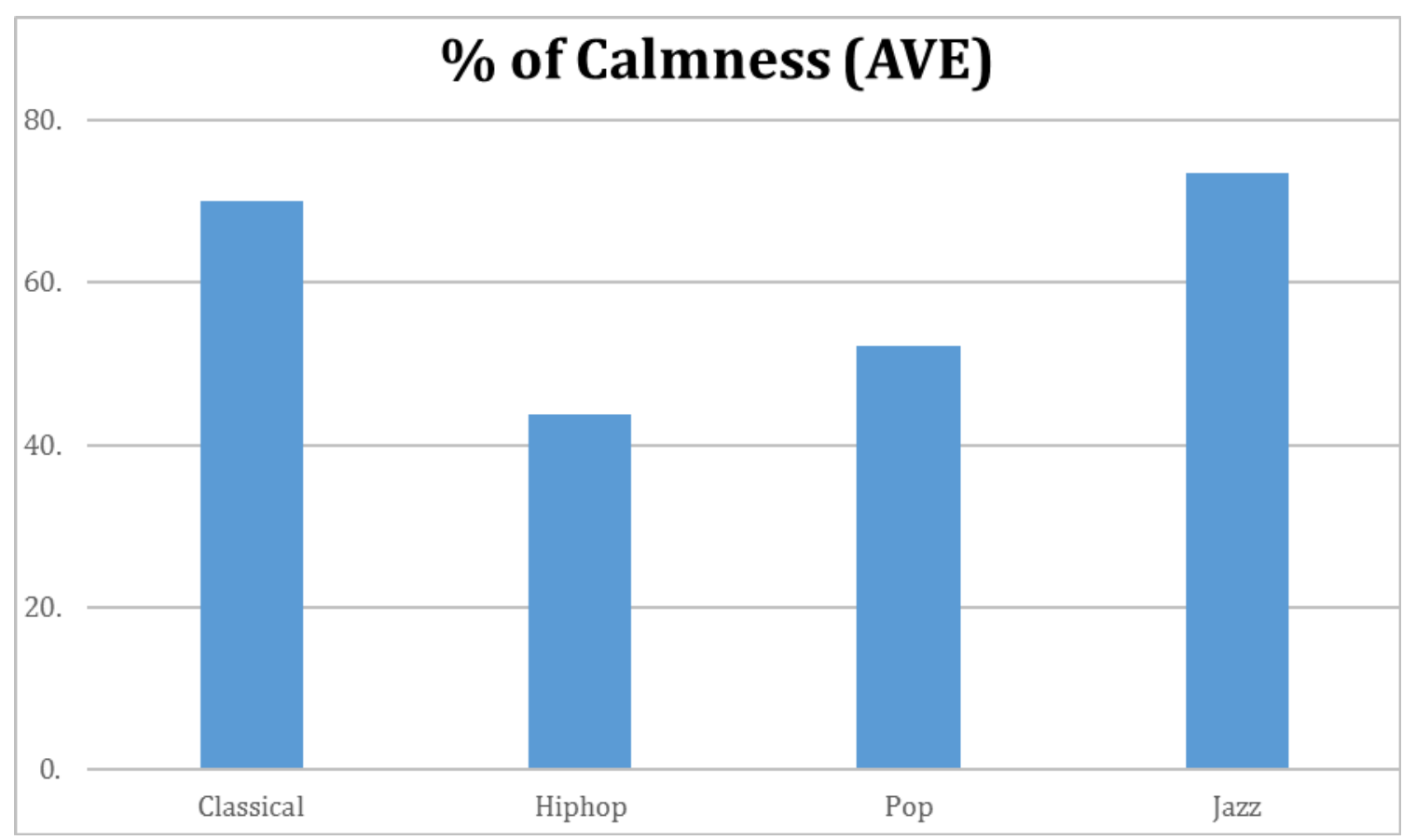

Figure 1. A comparison of calmness(EEG) between four genres of music

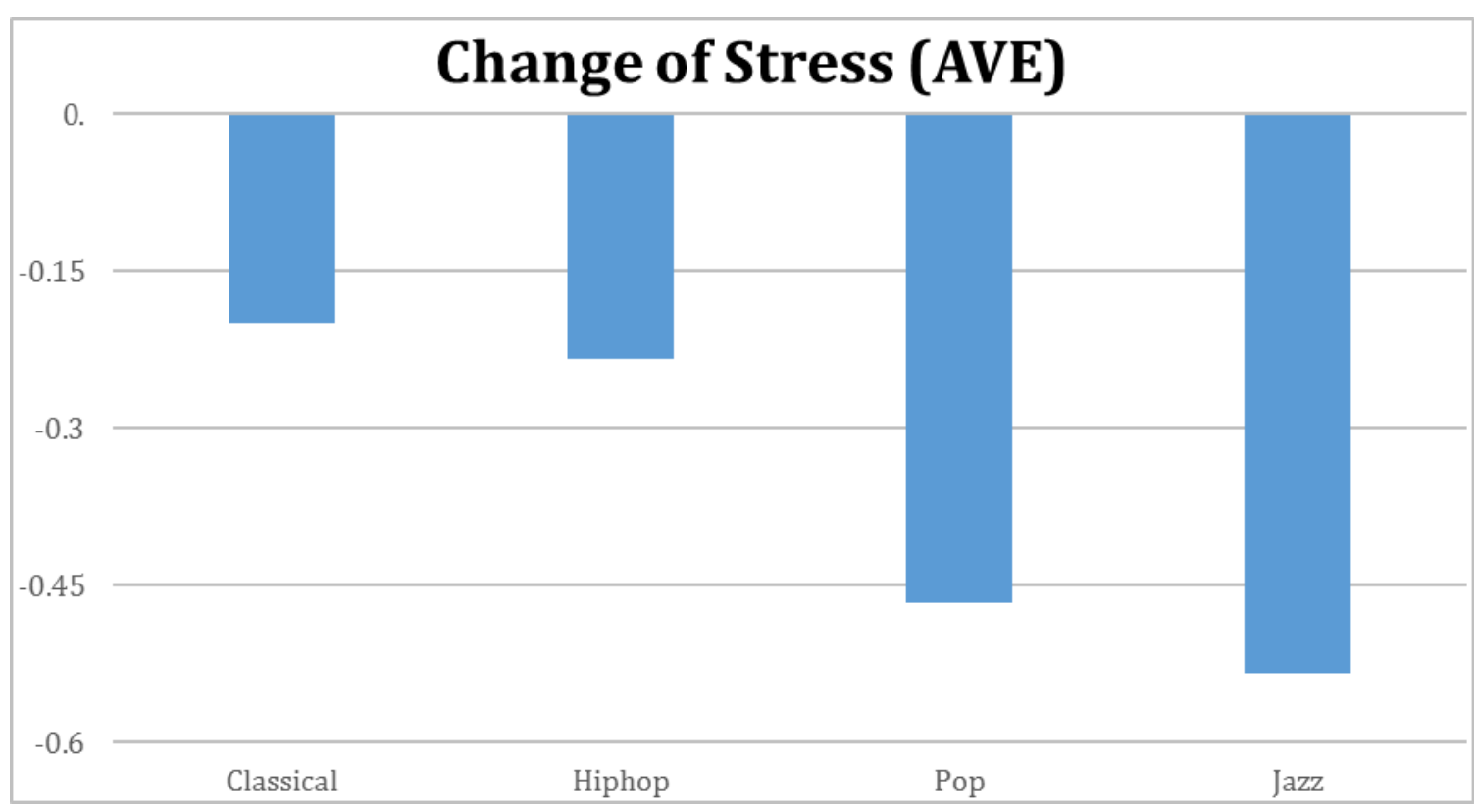

Figure 2. A comparison of improvement for stress level between four genres of music 


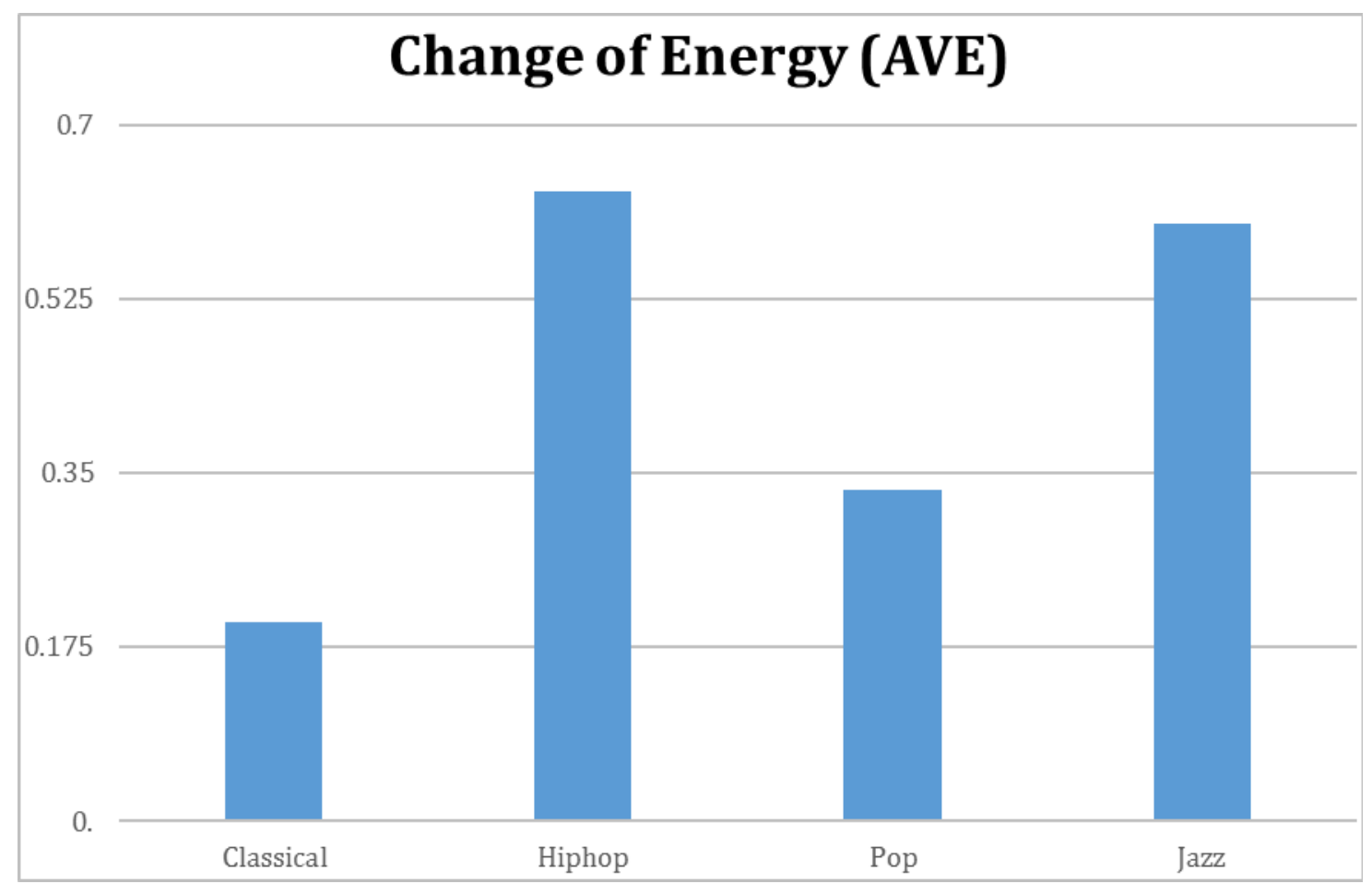

Figure 3. A comparison of improvement for energy level between four genres of music

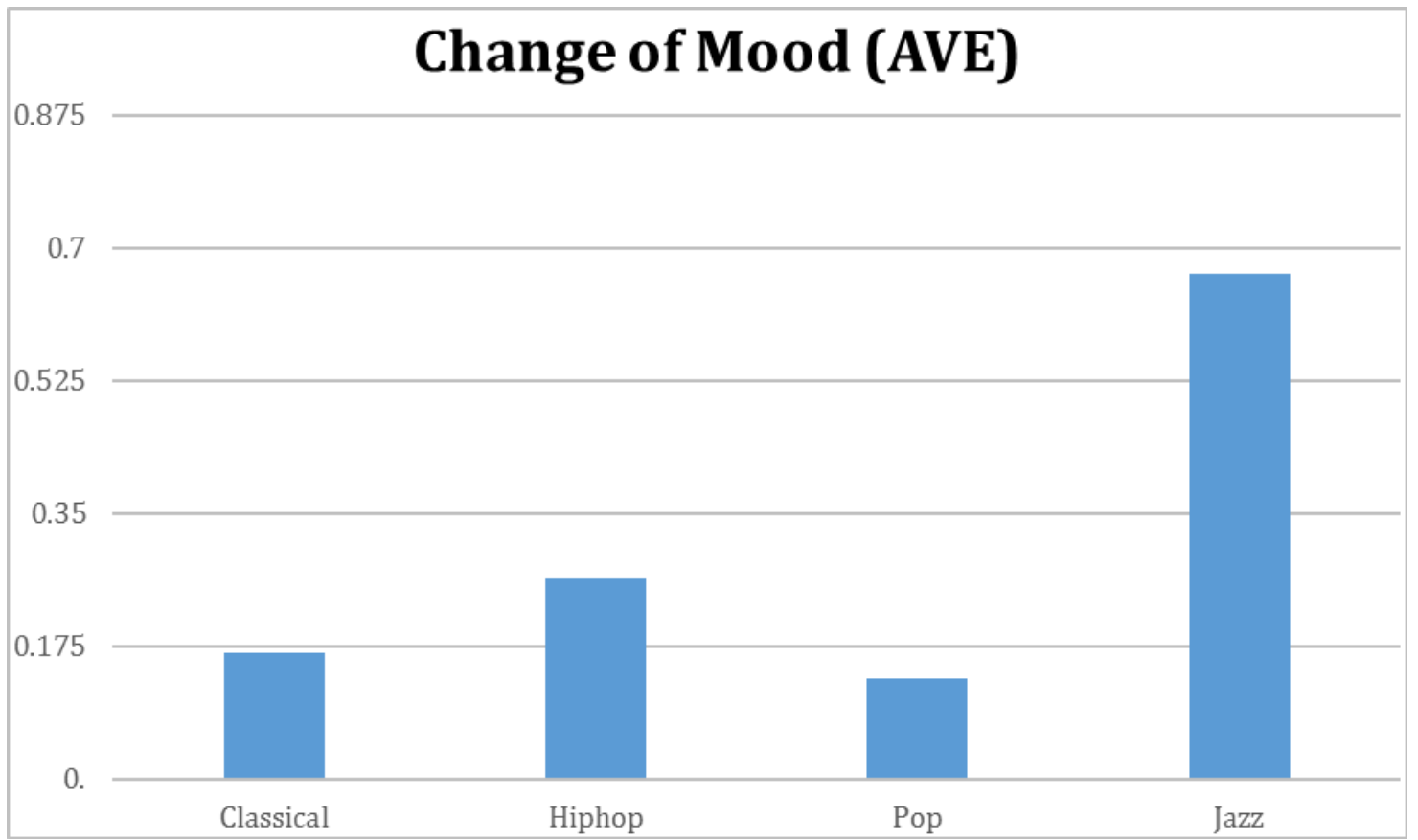

Figure 4. A comparison of improvement for mood between four genres of music 


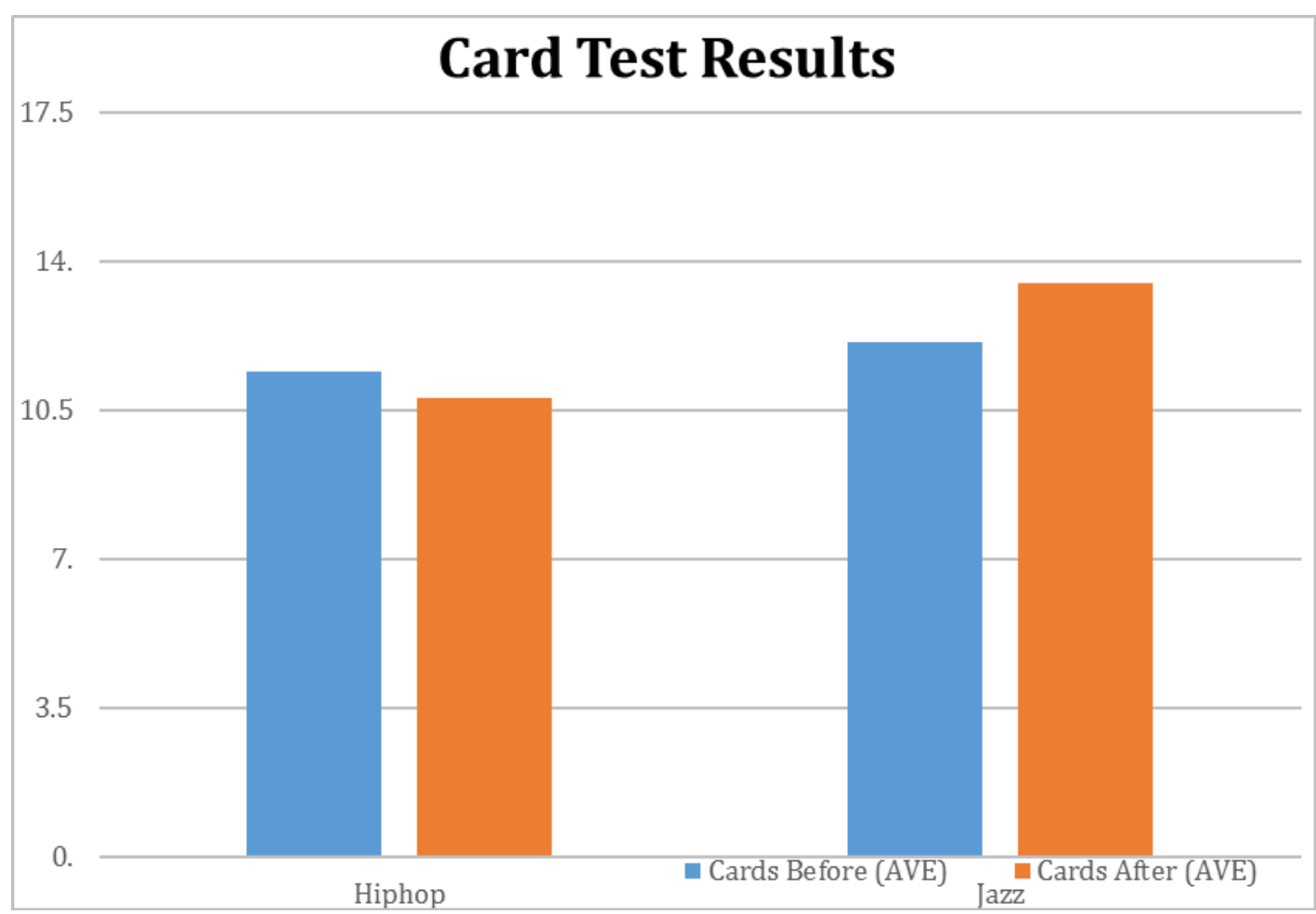

Figure 5. The comparison between card test results of Jazz and Hip-hop in Stage Two

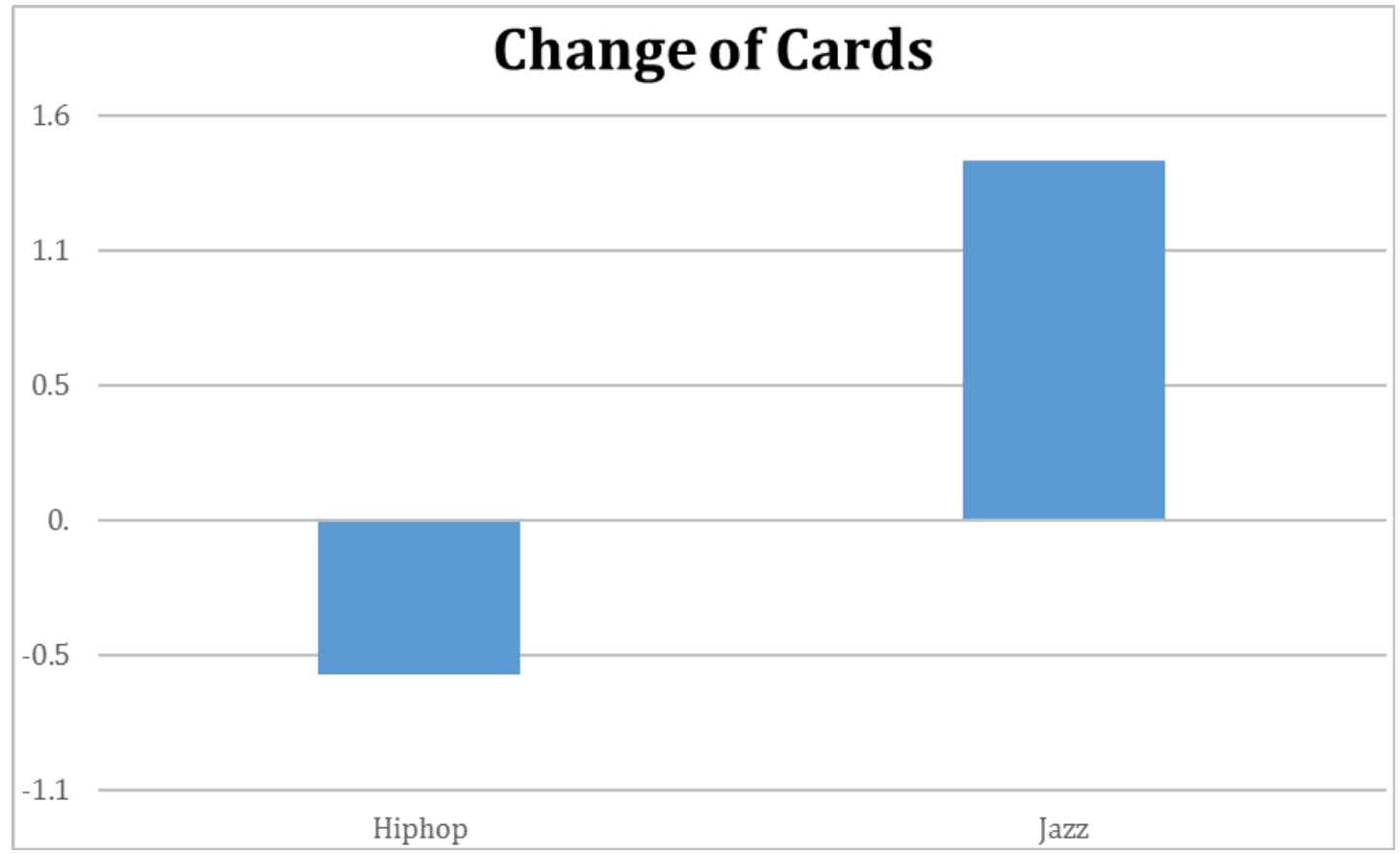

Figure 6. The comparison of change of cards for Jazz and Hip-hop in Stage Two 


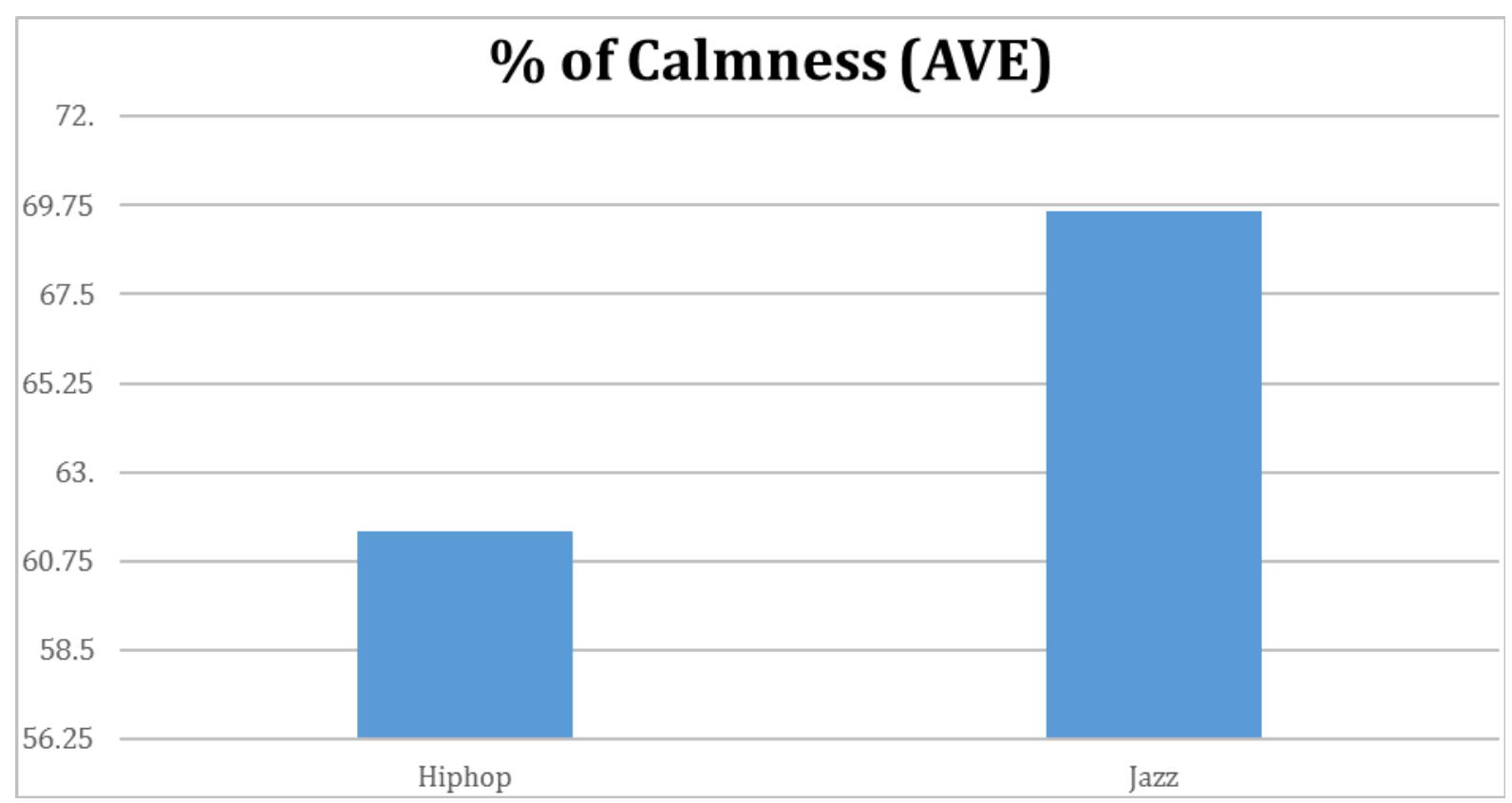

Figure 7. The comparison of calmness (EEG) Jazz and Hip-hop in Stage Two

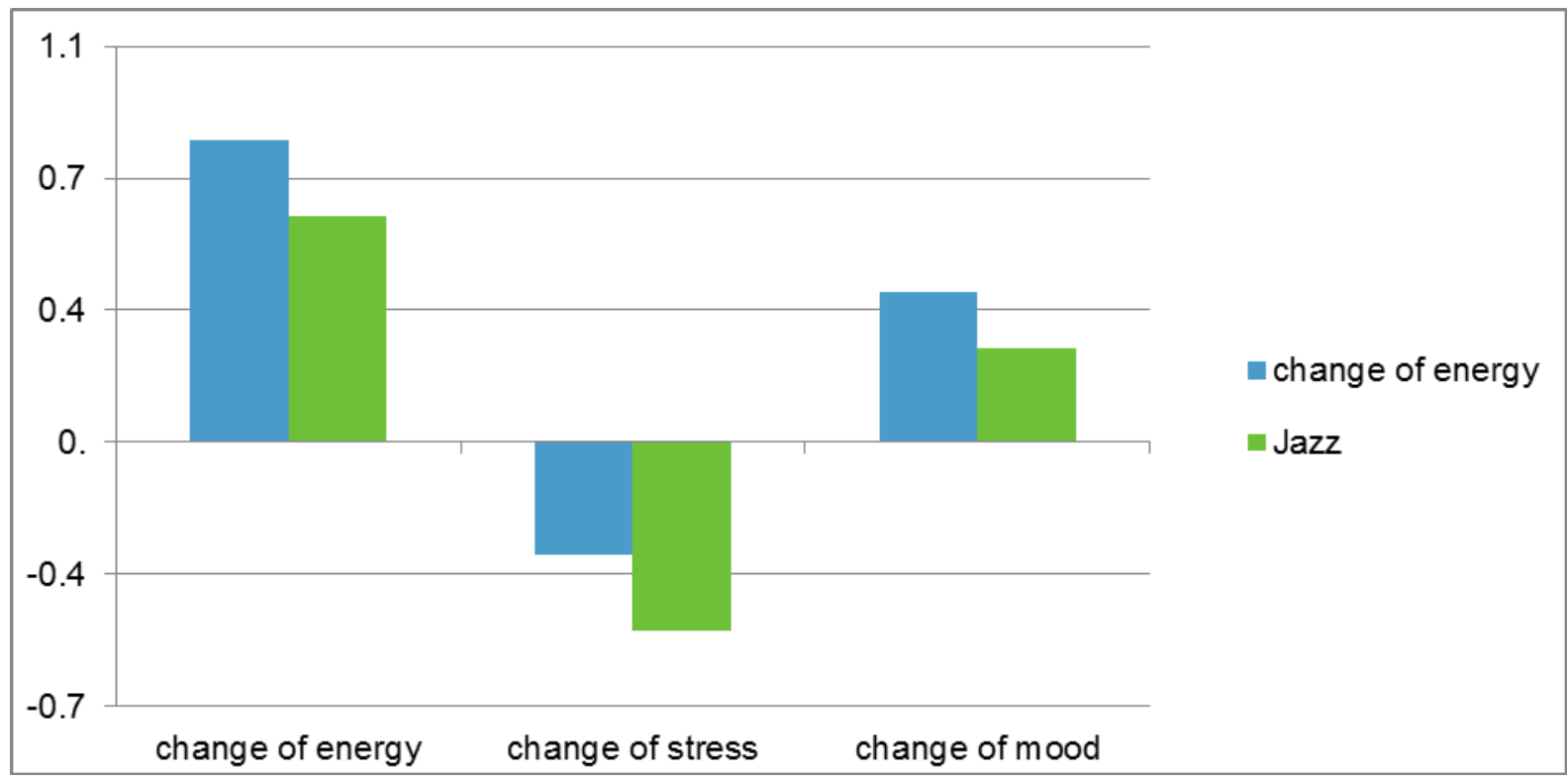

Figure 8. The comparison of change of mood, stress, and energy between Jazz and Hip-hop in Stage Two

\section{Discussion}

This research has several findings concerning the impacts of different genres of music on energy level, mood, stress level, calmness, and cognitive abilities as well as the correlations between these variables. In Stage One, the results indicated that Jazz had the largest impact on calmness and stress of the participants, which was also found in Stage Two of the experiment. Classical music had a relatively higher impact on calmness and usually caused participants to have lower energy. Pop had little to no effect on stress, energy, calmness, or mood improvement when comparing to the EEG and survey results of other genres of music. Hip-hop increased participants' energy level the most and had a positive impact on their mood. After comparing the results of the surveys, a correlation between energy, stress, mood, and calmness can be found between different genres of music. For all genres, the score for stress level improved when the calmness of the participants was relatively 
high during meditation. The mood of the participants improved when the score energy level improved. These findings may imply that calmness and stress are correlated and that energy and mood are correlated.

In Stage Two, Jazz had a positive impact on calmness and cognitive abilities, whereas Hip-hop had more negative effects on both categories. At the same time, participants who listened to Jazz were less energetic than participants who listened to Hip-hop music. Since both types of music had opposite effects on calmness, it is possible that the increment of calmness level has an increasingly positive effect on cognitive skills, and the increment of energy level has an adverse effect on cognitive skills. The results on changes in energy level and calmness span all genres of music in both stages, suggesting that the higher the energy level, the lower the calmness level. In other words, calmness and energy have a negative relationship with each other. Stress and mood did not demonstrate a direct relationship with cognitive skills.

However, in this experiment, there are several discrepancies of data between different genres of music in Stage One and Stage Two, such as the improvement for mood and stress levels. The discrepancies of results and data between the two stages might be caused by several factors, such as the inaccuracy of the survey, different conditions of participants, and the short experiment time. In Stage One, Jazz demonstrated a very high score on participants' energy level. Interestingly, when the calmness score of Jazz was relatively high, we would expect energy level to be low given that excitement and calmness are opposites. However, Jazz had a high score on both the change of energy level and calmness. Since calmness is measured by EEG and Muse headset, which are both stated to be reliable in prior research, the data on calmness is likely more accurate and reliable. The discrepancy between theoretical and actual results might be caused by the inaccuracy of the survey. Since the survey was elementary and quick, some participants might have given an inaccurate answer comparing to their actual condition on energy. The survey was also based on the feelings of participants on their conditions of energy, stress, and mood; thus, some participants might have given inaccurate or false feedback. This inaccuracy of survey data might have also caused the discrepancy in mood between the two stages: whereas Stage One showed that Jazz produced a significantly greater change in mood than Hip-hop, Stage Two showed the opposite. The survey's inaccuracy might also cause this discrepancy.

Although Jazz was better able to improve cognitive skills than Hip-hop, it is worth considering how the baseline cognitive abilities of participants could have impacted the results. Even though participants who listened to Hip-hop remembered fewer cards than participants who listened to Jazz in the cognitive test at the beginning of the experiment, this cannot necessarily be attributed to the music. Indeed, it is possible that the natural cognitive abilities of participants in the Jazz group are better than those in the Hip-hop group. The different cognitive abilities of participants might influence the results of cards remembered by participants positively or negatively.

Even though there are differences between the results of different genres of music between the two stages, the results of the research only showed a trend. T-tests comparing energy, stress, mood, and cognitive abilities from before and after the experiment all showed insignificant results. The differences of all dependent variables between each genre of music were also small in comparing the highest possible changes in those variables. However, since the results in Stage Two were consistent with energy, stress, mood, calmness, and cognitive test, the results seem to indicate a correlation or trend. This experiment might have also rendered more significant results if additional time had been dedicated to each session of music listening (meditation), since this would allow participants an opportunity to calm down and adjust their condition.

\section{Reference}

Ahtisaari, M., \& Karanam, K. (2015, July 21). Music and Emotion. Retrieved October 28, 2018, from Sync Project website: http://syncproject.co/blog/2015/7/21/music-and-emotion

Alstyne, D. V. (n.d.). Classical vs. Popular Music. Retrieved October 28, 2018, from davidvanalstyne website: http://davidvanalstyne.com/index.html

Bennett, V. (1942). Music and Emotion. The Musical Quarterly, 28(4), 406-414. https://doi.org/10.1093/mq/XXVIII.4.406

Blocka, K. (2017, September 14). EEG (Electroencephalogram). Retrieved October 28, 2018, from healthline website: https://www.healthline.com/health/eeg\#uses

Ciotti, G. (2014, July 11). How Music Affects Your Productivity. Retrieved October 28, 2018, from Fast Company website: https://www.fastcompany.com/3032868/how-music-affects-your-productivity

Ciotti, G. (2015, August 27). How Music Affects Your Productivity. Retrieved October 28, 2018, from HelpScout website: https://www.helpscout.net/blog/music-productivity/ 
Cox, R. (1990). A History of Music. The Journal of Aesthetics and Art Criticism, 48(4), 395-409. https://doi.org/10.2307/431576

Fuller, R. P. (2010, January 14). Classical Music. Retrieved October 28, 2018, from rpfuller website: https://www.rpfuller.com/gcse/music/classical.html

H., S. (n.d.). Why is Music Important to Human Beings? Retrieved October 28, 2018, from Life Advancer website: http://www.lifeadvancer.com/why-is-music-important-to-humans/

Herrmann, N. (2018, January). What is the function of the various brainwaves. Retrieved October 28, 2018, from Scientific America website: https://www.scientificamerican.com/article/what-is-the-function-of-t-1997-12-22/

Hohstadt, L. (n.d.). What Is "Classical Music"? Retrieved October 28, 2018, from Lowell Hohstadt website: http://lowellhohstadt.com/what-is-classical-music/

How Does Music Affect Teenagers. (2016, November 15). Retrieved October 28, 2018, from Pumpic website: http://pumpic.com/security/how-does-music-affect-teenagers/

Jena, S. K. (2015). Examination stress and its effect on EEG. International Journal of Medical Science and Public Health, 4(11). https://doi.org/10.5455/ijmsph.2015.23042015308

Jenkins, J S. (2001). The Mozart effect. Journal of the Royal Society of Medicine, 94(4), 170-2. https://doi.org/10.1177/014107680109400404

Knight, W. E., \& Rickard, N. S. (2001). Relaxing music prevents stress-induced increases in subjective anxiety, systolic blood pressure, and heart rate in healthy males and females. Journal of Music Therapy, 38(4), 254 272. https://doi.org/10.1093/jmt/38.4.254

Krigolson, O. E., Williams, C. C., Norton, A., Hassall, C. D., \& Colino, F. L. (2017). Choosing MUSE: Validation of a Low-Cost, Portable EEG System for ERP Research. Frontiers in neuroscience, 11, 109. https://doi.org/10.3389/fnins.2017.00109

Lee Y-Y, Hsieh S (2014) Classifying Different Emotional States by Means of EEG-Based Functional Connectivity Patterns. PLoS ONE 9(4): e95415. https://doi.org/10.1371/journal.pone.0095415

Lesiuk, T. (2005). The effect of music listening on work performance. Psychology of Music, 33(2), 173-191. https://doi.org/10.1177/0305735605050650

Lopes, F. (1991). Neural mechanisms underlying brain waves: from neural membranes to networks. $\begin{array}{llll}\text { Electroencephalography } \quad \text { and Clinical Neurophysiology, } & 79(2), & \text { 81-93. }\end{array}$ https://doi.org/10.1016/0013-4694(91)90044-5

Michelon, P. (2006, December 18). What are Cognitive Abilities and Skills, and How to Boost Them? Retrieved October 28, 2018, from Sharp Brains website: https://sharpbrains.com/blog/2006/12/18/what-are-cognitive-abilities/

Ogata, S. (1995). Human EEG responses to classical music and simulated white noise: Effects of a musical loudness component on consciouness. Perceptual and Motor Skills, 80(3, Pt 1), 779-790. https://doi.org/10.2466/pms.1995.80.3.779

Popular Music. (2012, December 28). Retrieved October 28, 2018, from New World Encyclopedia website: http://www.newworldencyclopedia.org/entry/Pop_music

R. Scott Heath. (2006). Hip_Hop Now: An Introduction. Callaloo, 29(3), 714-716. https://doi.org/10.1353/cal.2006.0145

Ramirez, R., Planas, J., Escude, N., Mercade, J., \& Farriols, C. (2018). EEG-Based Analysis of the Emotional Effect of Music Therapy on Palliative Care Cancer Patients. Frontiers in psychology, 9, 254. https://doi.org/10.3389/fpsyg.2018.00254

Randel, D. M. (2003). The Harvard Dictionary of Music (4th ed.). The Belknap Press of Harvard University Press.

Schellenberg, E. G., \& Weiss, M. W. (2013). Music and cognitive abilities. In D. Deutsch (Ed.), The psychology of music (pp. 499-550). San Diego, CA, US: Elsevier Academic Press. https://doi.org/10.1016/B978-0-12-381460-9.00012-2

Teplan, M. (2002). Fundamentals of EEG Measurement. Measurement Science Review, 2. Retrieved from http://www.edumed.org.br/cursos/neurociencia/MethodsEEGMeasurement.pdf 
Thoma, M. V., La Marca, R., Brönnimann, R., Finkel, L., Ehlert, U., \& Nater, U. M. (2013). The effect of music on the human stress response. PloS one, 8(8), e70156. https://doi.org/10.1371/journal.pone.0070156

Tierney, A. T., Krizman, J., Kraus, N., \& Tallal, P. (2015). Music training alters the course of adolescent auditory development. Proceedings of the National Academy of Sciences of the United States of America, 112(32), 10062-10067. https://doi.org/10.1073/pnas.1505114112

(2017). Music-Evoked Emotions-Current Studies. Frontiers in neuroscience, $11,600$. https://doi.org/10.3389/fnins.2017.00600

what does muse measure? (n.d.). Retrieved October 28, 2018, from choosemuse website: http://www.choosemuse.com

\section{Copyrights}

Copyright for this article is retained by the author(s), with first publication rights granted to the journal.

This is an open-access article distributed under the terms and conditions of the Creative Commons Attribution license (http://creativecommons.org/licenses/by/3.0/). 